\title{
Systematic literature review of modifiable risk factors for recurrent acute otitis media in childhood
}

\author{
José Faibes Lubianca Neto, ${ }^{1}$ Lucas Hemb, ${ }^{2}$ Daniela Brunelli e Silva ${ }^{3}$
}

\begin{abstract}
Objective: Review evidence about modifiable risk factors for recurrent acute otitis media.

Source of data: MEDLINE with no language restriction, from January 1966 to July 2005, using descriptors "acute otitis media/risk factors". Two hundred and fifty-seven articles were obtained. These included randomized clinical trials, cohorts, case-control and cross-sectional studies that contained analyses of modifiable risk factors for the development of recurrent acute otitis media as the main objective and with samples of individuals up to the age of 18 years. Except when relevant, the following were excluded: non-systematic reviews, reports of cases, series of cases, and medical society guidelines.

Summary of data: Nine risk factors linked to the host and eight linked to the environment were identified. Of the first group, allergy, craniofacial abnormalities, gastroesophageal reflux and the presence of adenoids were classified as modifiable. In the second category, upper airway infections, day care center attendance, presence of siblings/family size, passive smoking, breastfeeding and use of pacifiers were included. Afterwards, the risk factors were classified in accordance with levels of evidence.

Conclusions: The risk factors established for recurrent acute otitis media and capable of being modified were the use of pacifiers and care in daycare centers. The probable risk factors were privation of mother's milk, presence of siblings, craniofacial abnormalities, passive smoking and presence of adenoids. No modifiable factor was classified as unlikely. Among those that need further study are allergy, gastroesophageal reflux and passive smoking during gestation.
\end{abstract}

J Pediatr (Rio J). 2006;82(2):87-96: Acute otitis media, risk factors, review.

\section{Introduction}

Otitis media is inflammation of the mucosa lining the tympanic cavity. This article discusses the risk factors (RFs) for the acute form, defined as the association of the rapid appearance of local and systemic symptoms with signs of acute middle ear inflammation, which may have viral or bacterial etiology. It is classified as recurrent acute

1. Doutor. Professor adjunto, Fundação Faculdade Federal de Ciências Médicas de Porto Alegre (FFFCMPA), Porto Alegre, RS, Brasil. Coordenador, Serviço de Otorrinolaringologia Pediátrica, Hospital da Criança Santo Antônio (HCSA), Porto Alegre, RS, e Complexo Hospitalar Santa Casa de Porto Alegre (CHSCPA), Porto Alegre, RS, Brasil. Membro, Núcleo Gerencial, Departamento Científico de Otorrinolaringologia, Sociedade Brasileira de Pediatria, Rio de Janeiro, RJ, Brasil.

2. Médico residente, Serviço de Otorrinolaringologia, CHSCPA, Porto Alegre, RS, Brasil.

3. Médica estagiária, Serviço de Otorrinolaringologia, CHSCPA, Porto Alegre, RS, Brasil.

Manuscript received Sep 21 2005, accepted for publication Dec 142005.

Suggested citation: Lubianca Neto JF, Hemb L, Silva DB. Systematic literature review of modifiable risk factors for recurrent acute otitis media in childhood. J Pediatr (Rio J). 2006;82:87-96. otitis media (RAOM) when three episodes occur within a period of 6 months, or four episodes in a period of 12 months, with complete normalization of the otoscopy during the inter-crisis periods. ${ }^{1,2}$ Chronic otitis media with effusion (COME) is defined as otitis with persistent asymptomatic middle ear effusion, except by hypoacusia, for at least 3 months.

The RFs are not directly involved in the pathophysiology of otitis media, but when they are present, they result in increased risk of disease, probably because they influence one or more causal mechanisms. Among personal parameters, for example, race, sex and age influence the structure of the auditive tube or its function, while the age factor also determines the host's immunologic response. Evidently some of the factors are related. Younger children have more upper airway infections (UAI). They are also the only ones that lie on their backs to breastfeed and use pacifiers with greater prevalence. Inter-relations are hardly considered in some studies. Findings from different 
epidemiologic investigations may also vary, depending on the differences in the definition of RAOM, methods for identifying cases of RAOM, observation intervals, prevalence windows and population characteristics.

In this article, only the modifiable RFs for RAOM are discussed, which are frequently also those for COME.

\section{Material and methods}

A systematic review was made of studies about RFs for AOM and RAOM in childhood.

\section{Study inclusion and exclusion criteria}

In the review of original studies (cross-sectional, casecontrol and cohorts), the following were included: systematic reviews and meta-analyses, with the main objective of investigating RFs for AOM and RAOM, using samples with individuals up to the age of 18 years. Also included were two articles prior to 1966 because of their historical importance, and unpublished masters'/doctors' thesis data. Unless they were significant for discussion about some RFs, the majority of non-systematic bibliographic reviews and consensus or medical society guidelines, as well as case or series reports were excluded.

\section{Research strategy and review procedure}

A systematic review was made to identify studies that met the established inclusion criteria. To do this, the MEDLINE database from January 1966 to July 2005 was searched, with no restriction on language. The descriptors used were "acute otitis media/risk factors", and 257 articles were obtained. In addition, selected study references were examined in search of articles that might meet the selection criteria and that might have been overlooked in the initial search.

After reviewing the evidence associating modifiable RFs (110 articles) with RAOM, they were classified in accordance with the levels of evidence. RFs with level of evidence I were considered to be only RFs for which there were intervention studies, that is to say, when investigators actively reduced exposure to them in a random and controlled manner (randomized clinical trials). RFs classified as level of evidence II were those studies conducted through well delineated cohorts, meta-analyses of cohorts or cases-controls within cohorts with a significant number of children and control of the effects of the various RFs on the main association. RFs with level of evidence III were those studied through investigations with less discriminatory power than clinical trials and prospective cohorts (cases-controls of prevalent cases). RFs with level of evidence IV were those arising from cross-sectional or other observational studies not previously mentioned, while those with level of evidence $V$ were based on the recommendations of medical guidelines or specialist opinions without the above-mentioned evidence. ${ }^{3}$

\section{Results}

For didactic purposes, RFs were divided into two classes: associated with the host and associated with the environment. The most studied RFs associated with the host are as follows: age, prematurity, sex, race, allergy, craniofacial abnormalities, presence of adenoids and genetic predisposition. Environmental factors include the following: UAI, seasonality, care in daycare centers, presence of siblings (family size), exposure to passive smoking, breastfeeding, socioeconomic level and use of pacifiers. Of these, those linked to the host and are modifiable are the following: allergy, craniofacial abnormalities, gastroesophageal reflux (GER) and presence of adenoids. Modifiable environmental RFs include: UAI, day care center attendance, family size, exposure to passive smoking, breastfeeding, and use of pacifiers.

\section{Allergy}

Although there is epidemiologic, mechanical and therapeutic evidence showing that allergic rhinitis contributes to the pathogenesis of otitis media, there are still many doubts about their influence as RFs.

Kraemer et al., in a case-control study of prevalent cases, studied 76 cases submitted to typanotomy for the placement of ventilation tubes and 76 controls paired by age, sex and season of the year on admission to have general pediatric surgery performed. Compared with the control children, those that had middle ear effusion presented with approximately four times more complaints of atopic symptoms. ${ }^{4}$ Through a cohort of 707 children with AOM, without clearly defining what they considered to be "atopic manifestations", Pukander \& Karma found more persistent middle ear effusion for 2 months or longer in children with such manifestations than in those that were non-allergic. ${ }^{5}$ Tomonaga et al. found the presence of allergic rhinitis in $50 \%$ of the 259 Japanese children (mean age 6 years) in whom middle ear effusion was diagnosed. Middle ear effusion was present in $21 \%$ of the 605 children (mean age 9 years) in whom allergic rhinitis was diagnosed. The incidence of allergic rhinitis, middle ear effusion and both conditions was 17.6 and $2 \%$ respectively among a control group of 108 patients (mean age 6 years) in whom none of the conditions were previously diagnosed. ${ }^{6}$ In another study, 77 children who had chronic middle ear effusion, and who had had at least one ventilation tube placement performed were followed up. There was increased IgE in the middle ear effusion in 14 out of 32 children with allergic rhinitis, compared with two out of 45 children considered to be non-allergic. ${ }^{7}$ This finding, however, only allows the inference that the allergic have 
more IgE than the non-allergic, and that this IgE also affects middle ear effusion.

As is the case in some of the RFs that have been discussed, there are also well delineated articles on allergic rhinitis, which have not been able to demonstrate association. 8,9 When one counterbalances the weight of evidence for and against the association of allergic rhinitis and otitis media, publications with a less adequate investigative model tend to be on the side of accepting nasal allergy as a RF, which makes allergic rhinitis a RF that needs further study before more definitive conclusions can be drawn (level of evidence III).

\section{Craniofacial abnormalities}

There is higher incidence of otitis media in children with uncorrected cleft palate than in normal children, and it is frequent in the former, mainly when considering those aged up to 2 years. ${ }^{10,11}$ When, however, the cleft is corrected, otitis media recurrence is reduced, 11,12 possibly because it allows improved auditive tube function. ${ }^{13}$ In a retrospective cohort, Boston et al. demonstrated that the presence of craniofacial deformities increased the chance of the child requiring multiple interventions for ventilation tube placements. ${ }^{14}$

Otitis media is also more prevalent in children with craniofacial abnormalities and Down's syndrome. ${ }^{15}$ Approximately $59 \%$ of these patients had evidence of middle ear effusion. It was demonstrated that muscular hypotony, characteristic of the syndrome, could result in damage to the active opening function, as well as in very low auditive tube resistance. Nasopharyngeal secretions can thus have easy access to the middle ear. ${ }^{16,17}$ Otitis media is histologically and clinically prevalent in a series of other congenital diseases that go along with craniofacial malformation. 18

Although the literature is almost unanimous in favor of the association, since there are no studies with a large number of followed-up patients and with adequate methodology, the presence of craniofacial abnormality was classified as a probable RF (level of evidence IV).

\section{Gastroesophageal reflux}

Most of the evidence about the association of GER with RAOM are of level IV, and come from reports on cases or series and studies in animals. In 2001, four cases were reported of adults with chronic otitis media that was difficult to resolve and who, after diagnosis of GER had been confirmed by pHmetry and endoscopy, started treatment with omeprazol and had their conditions resolved. One of them, who had also presented with bilateral otorrhea for several years and had been diagnosed as having tympanic membrane atelectasis, became asymptomatic with omeprazol and soon after the drug was suspended, began to suppurate again. When the medication was reintroduced, the otologic suppuration was controlled again. 19

From 2002 onwards, another six studies with nonaligned results appeared. A randomized clinical trial compared the effects of a control saline solution infusion ( $n=10)$ with another experimental hydrochloric acid / pepsin solution ( $n=10$ ) in the rhinopharynx of rats, on the auditive tube function. There was significant repercussion on practically all the objective physiologic auditive tube parameters. Thus it was shown that experimentally simulated GER in animals is capable of causing dysfunction in the pressure regulation and mucocilliary depuration of the middle ear. ${ }^{20}$ In a study of 27 children with a mean age of 6.8 years and with chronic tubotympanic disorders ( 14 with chronic otitis media with effusion and 13 with RAOM), Rozmanic et al., by means of pHmetry, demonstrated pathologic GER in 15 of them (55.6\%). As a result of this finding, they recommended pHmetry, preferably double channel, in children who did not respond to conventional otitis media treatments. ${ }^{21}$ Tasker et al. measured the pepsin concentration in middle ear liquid samples. Of the 54 middle ear effusions studied, 45 (83\%) contained pepsin/pepsinogen at a concentration over 1,000 times higher in relation to the serum concentration. They concluded that the gastric juice reflux may be the major cause of middle ear effusion in children. ${ }^{22}$ In 65 effusion samples from children submitted to myringotomy, the same authors measured the total pepsin/pepsinogen protein concentration, fibrinogen concentration and albumin content, as well as the $\mathrm{pH}$ of the secretion and its proteolytic activity. In total, 59 of the 65 effusions were positive for antipepsin antibody (which also measured pepsinogen), once again with levels up to 1,000 time higher than the protein serum concentration. All the effusions also contained albumin and fibrinogen, but at levels within the normal serum reference level limits. Protease acid activity occurred in 19 (29\%) of the 65 effusions. The $\mathrm{pH}$ of the effusions ranged from 7 to 9 . The authors concluded that it is "almost certain that pepsin in middle ear effusions comes from acid content reflux and that there may therefore, be a role for anti-reflux therapy in the treatment of otitis media with effusion." 23 It should be remembered that this research group is mainly responsible for the enthusiasm about associating GER or gastrolaryngeal reflux with manifestations in upper airways (laryngomalacia, contact ulcer and vocal fold granuloma, rhinosinusitis, chronic pharyngotonsillitis, etc.), and always shows highly significant results, which other authors have frequently not been able to replicate. This is the case in the study of Antonelli et al., who measured the total pepsinogen concentration in 26 acute otorrhea samples after ventilation tube placement. Pepsinogen was found in eight samples, but at low concentrations; lower than normal serum 
levels. They concluded that GER does not play an important role in acute otorrhea after ventilation tube placement. 24 Whereas Pitkaranta et al., analyzing 20 children submitted to adenoidectomy and tympanotomy, analyzed the presence of Helicobacter pylori through serological tests to detect antigens and adenoid and middle ear effusion cultures. In total, $20 \%$ of the serological tests were positive; however, in none of the cases was there growth of the germ in adenoid or middle ear cultures. Although the inference is limited, as no control group was presented, this study was not able to show association by using bacteria as an indirect marker of gastric fluid reflux into the middle ear. 25

It is true that as far back as 1963 , it was possible to demonstrate radiographically that the fluid from the rhinopharynx can penetrate the nasopharyngeal orifice of the tube during deglutition under physiologically normal conditions. ${ }^{26}$ Similarly, it is known that exposure of the auditive tube to $\mathrm{pH}<4$ results in ciliostasis, ${ }^{27}$ harming mucocilliary depuration, and increasing the chance of effusion accumulating in the middle ear. In addition, it has been demonstrated that exposure to gastric juice causes inflammation, edema and even respiratory epithelium ulceration, ${ }^{28}$ which in turn may also favor the appearance of otitis media by harming the tubal function. However, the extrapolation of these results to the clinic, as has been shown, still lacks better delineated studies. While these publications are awaited, it is prudent to classify GER as a RF under study for RAOM (level of evidence IV).

\section{Adenoids}

Those that defend the association between adenoid tissue hyperplasia and RAOM or COME base it on three types of evidence. There are those that prefer articles pointing out great correlation (approximately 70\%) between the rhinopharyngeal bacteria and those cultivated in the middle ear in acute episodes ${ }^{29}$ or those that point towards a larger number of colony counts in adenoid cultures coming from cases operated on for RAOM as compared with those operated on for obstruction. ${ }^{30}$ The theory that adenoids functioning as a bacterial reservoir is more accepted currently than the theory of mechanical obstruction of the tube by adenoidal growth, a fact rarely proved in the clinic. ${ }^{31}$ Others prefer to base themselves on the third type of evidence, that is to say, on randomized clinical trials that demonstrated the positive effect of adenoidectomy on reducing various conclusions related to otitis media.32-35 Boston et al., when studying 2,121 children that had ventilation tube placement performed, demonstrated that approximately $20 \%$ of them required re-intervention for tube placement. Analyzing predictive factors for second surgery, it became clear that if adenoidectomy were associated with the first surgery, the need for re-intervention would be substantially reduced
( 0.08 versus $0.24 ; p<0.001) .{ }^{14}$ Jero \& Karma, studying 165 children aged from 5 months to 12 years, diagnosed with COME, attempted to identify factors that would predispose them to the persistence of larger pathogens (S. pneumoniae, H. influenzae, M. catarrhalis, S. pyogenes) in the middle ear for a longer time. Among the children adenoidectomized early, the proportion of those with these pathogens in the effusion was $8 \%$, compared with $32 \%$ of non-adenoidectomized children ( $p=0.02)$. $S$. pneumoniae, $B$. catarrhalis or $S$. pyogenes were not cultivated in any of the adenoidectomized children, while they grew in $25 \%$ of the non-adenoidectomized children $(p<0.001) \cdot 36$

However, there are well delineated and well conducted randomized clinical trails with conflicting results, demonstrating that adenoidectomy alone or associated with ventilation tube placement does not play a role in the prophylaxis of RAOM in children younger than 2 years, 37,38 at least at the first ventilation tube placement. 35

As a conclusion, there are no original studies dealing with adenoid hyperplasia and risk of RAOM or COME, the suggestion coming from the opinion of specialists (level of evidence $\mathrm{V}$ ). The evidence comes from indirect studies that assess the effect of adenoidectomy on events related to otitis media. It would seem that adenoidectomy is more efficient in the treatment of COME than in RAOM, and the majority of authors agree that adenoidectomy must be performed, irrespective of the size of the adenoids, ${ }^{39}$ at least when the second ventilation tube placement is performed (level of evidence I).

\section{Environmental factors}

Upper airway infections

Both epidemiologic evidence and clinical experience strongly suggest that otitis media is frequently a complication of UAI. The incidence of COME is greater during autumn and the winter months, and less in summer in both hemispheres, 40,41 parallel to the incidence of $\mathrm{AOM}^{42,43}$ and UAI. 40,41 This evidence supports the assumption that UAI play an important role in the etiology of otitis media (level of evidence II).

Studies that spent time to isolate middle ear effusion virus in children showed viral antigens and even live viruses. ${ }^{44,45}$ Among the various mechanisms by which UAI may predispose patients to RAOM and COME, are inflammation and harm to the mucocilliary movement of the epithelium that lines the auditive tube, which has been experimentally 46 and clinically demonstrated. 47

\section{Day care center attendance}

Today day care center attendance is the major RF for developing RAOM. ${ }^{48}$ Various studies have shown that staying at a day care center is a RF for AOM. ${ }^{49-55}$ Alho et 
al. examined questionnaires that were sent to 2,512 randomly selected Finnish children's parents and also reviewed their clinical record cards and found an estimated relative risk (RR) of 2.06 (95\%CI 1.81-2.34) for development of AOM in children that frequented daycare centers when compared with care in their own homes. ${ }^{48}$ It was also demonstrated that children in daycare centers are more prone to needing ventilation tube placement than children cared for at home. In another analysis, the risk found for COME was 2.56 (95\%CI 1.17-5.57). ${ }^{49}$ Few studies have not been able to demonstrate association between AOM or COME and care outside of the home, and the majority of these are subject to methodological errors. 4,42

It would appear that the type of place where the child is cared for also interferes in the association. It has been shown that the susceptibility AOM diminished in a group of children who are cared for in family homes, in comparison with day care center attendance.8,56,57 In truth, the prevalence of negative pressure in the middle ear and Type B tympanograms, indicative of effusion in the middle ear, are greater in children cared for in day care centers with many others; intermediate in children cared for in family homes with fewer "companions" and less still in children cared for at home. ${ }^{58,59}$ In the meta-analysis of Uhari et al., the risk of AOM also increased with child care outside the home (RR 2.45; 95\%CI 1.51-3.98) and although on a lower scale, also with care in family homes (RR 1.59; 95\%CI 1.19-2.13). ${ }^{60}$ It is postulated that the risk is proportional to the number of "companions" the child is in contact with. $8,56,57$ A possible mechanism is related the greater number of UAI presented by children that are exposed to many other children. ${ }^{61}$ In conclusion, there would appear to be no doubt here, day care center attendance is a RF for RAOM and COME 62 (level of evidence II).

\section{Family size (siblings)}

Greater incidence of AOM and COME is described in children belonging to big families (especially if many of them are under 5 years of age) ${ }^{62-64}$ History of RAOM in siblings is considered to be a RF. 65 In a prospective cohort of Casselbrant et al., the order of birth was associated with the rate of otitis media episodes and with the percentage of time with middle ear effusion. 66 The first child had a lower incidence of AOM and less time with middle ear effusion in the first two years of life than the others with older siblings. Belonging to a younger generation among siblings was significantly related to RAOM, with a chance ratio of 4.18 (95\%CI 2.74-6.36). ${ }^{67}$ Pukander et al. also showed that children with siblings were more prone to recurrent episodes of AOM. ${ }^{8}$ Having more than one sibling was significantly related to the early onset of otitis media. ${ }^{68}$
However, the findings are not unanimous. A populational study by Vinther et al. did not demonstrate that family size was a RF for otitis media. ${ }^{69}$ This was also not demonstrated in the classical cohort of Teele et al. ${ }^{70}$ Black showed that the number of siblings had no influence on the frequency of otitis media in the child. ${ }^{71}$

As it is very difficult to separate the influence of genetics from care in day care centers and the socioeconomic level itself (families with lower purchasing power tend to be larger) from the exclusive effect of the number of siblings, this RF was classified is unlikely (level of evidence II).

\section{Passive smoking}

The majority of authors and some international committees $1,8,62,63,72$ accept passive smoking as an established RF for RAOM and COME. However, on deeper analysis of the original articles, it would appear that the subject is not closed. ${ }^{73}$ Evidence comes from crosssectional, case-control and cohort studies.

The first evidence is from 1978 and influences the appearance of various cross-sectional and case-control studies. Although it had another primary object, it showed only that the tendency to smoke and age influenced the prevalence of middle ear effusion. ${ }^{74} \mathrm{~A}$ year later, Vinther et al., conducted a population-based cross-sectional study with 527 children $^{69}$ and did not demonstrate the influence of passive smoking on either COME or AOM. The first casecontrol with positive results came in $1983 .{ }^{4}$ The chance ratio found for COME in children with two or more smokers at home was 2.8 (95\%CI 1.1-7.0). Children exposed to smoke from three or more packs of cigarettes/day had a chance ratio of 4.1 (95\%CI 0.9-19.2). In 1985, Black, in another case-control, found a chance ratio of 1.52 (95\% CI $1.06-2.21$ ) to 1.64 (95\%CI $1.03-2.61)$, depending on the control group analyzed. ${ }^{75}$ In Strachan's fist cross-sectional study, the prevalence of otalgia or otorrhea did not differ statistically in children exposed to no, one or two or more smokers (23.5, 25.3 and $24.4 \%$, respectively). ${ }^{76}$ Later, they studied 736 selected children and found a prevalence ratio of 1.14 by univariate analysis (95\%CI $1.03-1.27$ ). Whereas in the multivariate analysis, the risk diminished to 1.13 (95\%CI 1.00-1.28). ${ }^{77}$ Birch \& Elbrond, in 1987, studied 217 children randomly selected from the population and were unable to demonstrate association among the variables. ${ }^{78}$ Hinton \& Buckley conducted a case-control study that was the second specifically designed to test the association of passive smoking with COME. The chance ratio was 2.24, but without statistical significance. ${ }^{79}$ Another case-control appeared in 1993, with 85 cases and 85 control aged under 5 years. Controlling for other known RFs for otitis media, a chance ratio of 2.68 (95\%CI 1.27$5.65)$ was obtained. Evident association was noted between increased exposure and increased risk of COME episodes. 
The etiologic fraction of the population indicated that over $34 \%$ of RAOM cases were due to exposure to passive smoking. ${ }^{80}$ In 1995, Kitchens published a case-control study with 175 children of up to 3 years old with various types of otitis media with surgical indication. Of the various associations tested, only the presence of at least one resident smoker with the occurrence of ventilation tube placement had threshold statistical significance (chance ratio $1.66 ; 95 \% \mathrm{CI} 1.0-2.74$ ) ${ }^{81}$ In addition to the limitations with regard to sample selection, conclusions that came from detailed reading of the figures and tables presented, did not always agree with those of the authors. In 1999, Lubianca Neto et al., through a cross-sectional study with 192 children of up to 3 years of age, were unable to show greater prevalence of AOM, only nonrecurrent now, in children exposed to passive smoking (prevalence ratio $0.82 ; 95 \%$ CI $0.67-1.02) .82$ In 2001, Ilicali et al. presented a case-control study with 114 incident patients ranging between the ages of 3 and 8 years, requiring tympanostomy tubes because of RAOM or COME. The controls were 40 children paired by age. Exposure to tobacco smoke was assessed by urinary cotinine. Around $74 \%$ of the children in the group of cases and $55 \%$ in the control group were exposed to passive smoking ( $p=0.046) .83$ Finally, in 2002, Lieu \& Feinstein, through a cross-sectional population study assessing 11,728 children under the age of 12 years, showed that the occurrence of no otologic infection was increased by exposure to passive smoking, with adjusted prevalence ratio of 1.01 (95\%CI $0.95-1.06)$. This result confirms that of other studies that also did not demonstrate any increased risk for non-recurrent AOM. However, this risk was slightly increased by gestational exposure (prevalence ratio of $1.08 ; 95 \%$ CI $1.01-1.14)$ and by the combined exposure to tobacco smoke (adjusted prevalence ratio $1.07 ; 95 \% \mathrm{CI}$ 1.00-1.14). The risk of RAOM, however, was significantly increased with combined exposure (prevalence ratio 1.44; $95 \%$ CI $1.11-1.81) .84$

As from 1985, with the study of Iversen et al., the prospective cohorts began to appear. Studying 337 children recruited in day care centers, they demonstrated smoking as a risk for COME, with the additional finding that the risk associated with passive smoking increased with age. ${ }^{85}$ In the same year, the first study exclusively designed to test the hypothesis that passive smoking was a RF for COME appeared. Etzel conducted a retrospective cohort of 9 years with 132 day care children. He measured exposure to passive smoking through the salivary cotinine concentration. The rate of incidence of gross middle ear effusion density was 1.39 (95\%CI $1.15-1.69)$ and 1.38 (95\%CI 1.21-1.56) in the first year and in the first three years of life, respectively. However, the significance disappeared with the introduction of other variables in the logistic regression. ${ }^{86}$ Zielhuis et al., related a cohort of
1,493 children. The RR found for COME was 1.07 (95\% CI $0.90-1.26)$ in children exposed to passive smoking. ${ }^{87}$ In 1993, follow-up of 698 children demonstrated that the presence of smokers and increase in the number of packs of cigarettes smoked daily in the house increased the time with middle ear effusion. ${ }^{88}$ In 1995 , Ey et al. ${ }^{89}$ prospectively analyzed 1,013 children from birth to 1 year old, demonstrating that the mothers' heavy smoking (20 or more cigarettes/day) was a significant RF for RAOM, with RR of 1.78 (95\%CI 1.01-3.11) in the multivariate analysis. There was no increase in the risk of non-recurrent AOM. Greater effect of smoking on low weight $(<3.5 \mathrm{~kg})$ in the newborn was demonstrated, in which the risk of RAOM tripled in those exposed and more importantly, they were able to demonstrate that the mothers' smoking was the risk determinant. ${ }^{90}$ In another prospective cohort involving 918 children, it was demonstrated that children whose mothers smoked 20 or more cigarettes a day were at significantly increased risk of having four or more episodes of AOM (RR 1.8; 95\%CI 1.1-3.0) and of having the first episode of AOM much earlier (RR $1.3 ; 95 \%$ CI 1.0-1.8), after adjustments. The risk of RAOM increased parallel to the number of cigarettes smoked. ${ }^{91}$ In 1999, Daly et al., were unable to demonstrate association between the early onset of AOM and the rate of cotinine-creatinine in urine. ${ }^{68}$

Two meta-analysis spent time to study the association of passive smoking with RAOM and chronic otitis media with effusion. The first was Uhari et al., demonstrating a significant increase of $66 \%$ (RR 1.66; 95\%CI 1.33-2.06). ${ }^{60}$ Whereas Strachan \& Cook demonstrated estimated relative risks, if at least one of the parents smoke, of 1.48 (95\% CI 1.08-2.04) of RAOM, of 1.38 ( $95 \% \mathrm{CI} 1.23-1.55$ ) for middle ear effusion and 1.21 (95\%CI $0.95-1.53)$ for COME. 92

In conclusion, although some authors declared the relation between RAOM and COME with passive smoking as established, 93 others are totally against such affirmation. ${ }^{94}$ It may be said that passive smoking does not increase the chance of non-recurrent AOM (level of evidence IV). With regard to recurrent AOM and COME, passive smoking was classified as a probable RF (level of evidence II).

\section{Breastfeeding}

The majority of researchers believe that breastfeeding protects against otitis media. There are well-conducted cohorts focused on this, demonstrating that children fed on cows' milk have greater incidence of otitis media than those that are breastfed. In the prospective cohort of Saarinen, children that were breastfed up to 6 months of age did not have any episode of AOM, while $10 \%$ of those that started with cows milk before they were 2 months old presented with such episodes in this period. At the end of the first year, the incidence of two or more episodes of 
otitis was $6 \%$ in the first and $19 \%$ in the second group. From the end of the first up to the third year, four or more episodes of otitis occurred in $6 \%$ of breastfed children, compared with $26 \%$ of those artificially fed. Although there were many losses in the study, it was shown that prolonged breastfeeding ( 6 months or longer) protects the child against RAOM up to the third year of life. The group that used cows' milk had the first AOM episode much earlier. ${ }^{95}$

The two retrospective studies of Cunningham demonstrated less occurrence of otitis in the first year of life in breastfed children, in comparison with those fed with cows' milk (3.4 episodes per 1,000 patients/week against 6.3 , respectively). There was a strong tendency (10 in the first group and 64 in the second), but no significance. ${ }^{15}$ The second study, comprising 503 patients, found 3.7 and 9.1 episodes per 1,000 patients/week for the breastfed and artificially fed groups respectively. In this study, with more adequate control of confusion factors, significant difference was shown (total number of episodes - 23 against 182). 96

Case-control studies conducted in India and Canada, also showed a significantly lower number of episodes of otitis in the first two years in breastfed children in comparison with those that were fed with cows' milk $(0.3$ episodes (9/30) compared with the 2.9 (86/30) episodes). 97 However, the relation may have been under- or overestimated, as only children with otorrhea, with or without fever and irritability, or those who put their hands on their ears, were considered to have AOM, since these symptoms have low sensitivity and specificity for diagnosing AOM. 98 Stahlberg, in a case-control study with 115 children "prone to otitis", hospitalized to have adenoidectomy performed, demonstrated association between the duration of breastfeeding and age of introduction to cows' milk with RAOM. This study was limited mainly by its external validity. ${ }^{9}$ Duncan et al. followed up 1,013 nursing infants for 1 year and demonstrated that those that were exclusively breastfed for 4 months or longer, had half the number of AOM episodes, compared with non-breastfed infants, and $40 \%$ less otitis than those that were breastfed for less than 4 months. ${ }^{99}$ A cohort of 306 children followed up for the first two years demonstrated that between 6 and 12 months of age, the cumulative incidence of first episodes increased from 25 to $51 \%$ in exclusively breastfed infants and from 54 to $76 \%$ in nursing infants fed on formulas since birth. The peak of AOM incidence and middle ear effusion was inversely related to the breastfeeding rates beyond 3 months of age. There was double the risk for the first episode of AOM in nursing infants exclusively fed on formulas, compared with nursing infants exclusively breastfed for 6 months during this same period of life. 100

However, not all of the studies showed positive results. Paine \& Cable, in a retrospective cohort of 106 nursing infants during the first year of life, showed no significant difference in the number of otologic visits among children that were exclusively breastfed, breastfed with supplementary feeding and bottle-fed only (6, 9 and 23, respectively). At least two other studies also did not find any association between the duration of breastfeeding and the AOM recurrence rate. 101,102

One of the mechanisms involved in the association between breastfeeding and otitis media is "positional otitis media," according to which, children breastfed in an unsuitable position (lying down) are at greater risk for otitis media. ${ }^{103,104}$ A cohort with 698 children followed up from birth to 2 years of age demonstrated that the supine breastfeeding position was associated with earlier onset of COME. ${ }^{92}$ Saarinen also suggested this mechanism. ${ }^{95}$

In conclusion, the majority of the studies, corroborated by findings of meta-analyses showing that children breastfed for at least 3 months reduced the risk of AOM by $13 \%$ (RR $0.87 ; 95 \%$ CI $0.79-0.95$ ), 60 demonstrate that breastfeeding has a protective effect against middle ear disease (level of evidence II). However, there is controversy with respect to the optimal duration of breastfeeding required for protection. A study that focused on the duration of the protection given by breastfeeding after it ceases, demonstrated that the risk of AOM is significantly reduced for up to 4 months after it stops. Approximately 12 months after breastfeeding has stopped, the risk is virtually the same among those that were or were not breastfed. 105

\section{Use of pacifier}

Niemela et al., in a sample of 938 children, demonstrated that those that used pacifiers had a greater risk of presenting with four or more episodes of AOM than those who did not use them. ${ }^{106}$ Following-up 845 day care children prospectively, Niemela et al., found that the use of a pacifier increased the annual incidence of AOM, and was responsible for $25 \%$ of the episodes of the disease. 107 Warren et al. demonstrated that pacifier sucking was significantly associated with otitis media from the sixth to the ninth month and presented a strong trend towards statistical significance in the period from 9 to 12 months $(p=0.56) .{ }^{108}$ Lastly, in the meta-analysis of Uhari et al., the use of a pacifier increased the risk for AOM by $24 \%$ (estimated RR $1.24 ; 95 \%$ CI 1.06-1.46) ${ }^{60}$ (level of evidence II). As will be seen later on, classification of the level of evidence changes from II to I if a randomized clinical trial is included, assessing the effect of suspending the use of the pacifier on the incidence of recurrent AOM. 109

\section{Effects of interventions on the risk factors}

Every time risks are calculated in cohort studies, the risk attributable to a certain factor under study for the 
development of the expected outcome can be calculated. In other words, to what extent the incidence of a certain event or condition was due to the RF under study. This calculation only makes sense for modifiable RFs. Alho et al., in a population based study involving 825 targetchildren followed up for 2 years out of a total sample of 2,512 , calculated a fraction in excess of or attributable to the RFs most commonly reported for otitis media. One child out of every five could have escaped having otitis media if it had been moved from a day care center to care at home, and two out of every five affected could have escaped from recurrent episodes. Corresponding figures for care in family homes were lower: one and two nursing infants out of the total of every six affected, respectively. The parents stopping smoking and breastfeeding would have fewer effects. In any event, approximately $14 \%$ of all the episodes of otitis media could have been avoided if all the children were cared for at home. ${ }^{110}$

Encouraged by this type of reasoning, two groups of investigators invested in research to actively modify the exposure of children to the pacifier use $\mathrm{RF}^{109}$ and care in day care centers ${ }^{111}$ and analyzed the effect on the occurrence of otitis media (level of evidence I).

Through an open randomized clinical trial, 14 baby welfare clinics were paired in accordance with the number of children and social class of the parents they served. One clinic in each pair was randomly allocated for intervention, while the other served as control. Intervention consisted of a leaflet explaining the deleterious effects of pacifier use and gave instructions for restricting it (basically to use the pacifier only at the time of going to sleep). The total of 272 children under 18 months of age were recruited from the intervention clinics and 212 from control clinics. After intervention, there was a $21 \%$ decrease in continuous pacifier use from 7 to 18 months of age ( $p=0.0001)$, and the occurrence of AOM was $29 \%$ lower among children from the intervention clinics. The children that did not use the pacifier continually in any of the clinics had 33\% fewer episodes of AOM than the children that used them. ${ }^{110}$

The second study, also an open randomized clinical trial with a duration of 15 months, took the time to analyze the results of implementing the infection prevention program in 20 day care centers. This program was implemented in 10 centers and another 10 day care centers served as control. Data about the occurrence of infections and absences from the center or work because of infections among the children, their parents and the day care center staff were noted. Both the children and the staff had significantly fewer infections than the persons at the control centers, with a reduction of $9 \%(95 \% \mathrm{CI}$ $4-16 \%, p<0.002$ ) among 3 -year old children and $8 \%$ ( $95 \%$ CI $0-14 \%, p=0.049$ ) among older children. Children at the intervention centers received $24 \%$ fewer antimicrobial prescriptions (95\% CI $22-27 \%$, p < 0.001).
Thus, there were 2.5 fewer man/year absences from work on the part of parents, due to the illness of their children during 1 year at the program centers, a difference of $24 \%$ (95\%CI 18-29\%, p < 0.001).

These latter two studies underline the usefulness of investing in investigations that increasingly seek to elucidate the most important RFs for propensity to otitis media, mainly RAOM and COME, in an attempt to discover RFs in which it is possible to intervene. This could bring about gains in many different spheres: a child that will be at less risk of having otitis, parents that would tend to lose fewer work days because of their children's illness, less use of antibiotics, favoring the reduction of bacterial resistance and cost reductions to families and to the health system.

\section{References}

1. Rovers MM, Schilder AG, Zielhuis GA, Rosenfeld RM. Otitis media. Lancet. 2004;363:564-73.

2. Aronovitz GH. Antimicrobial therapy of acute otitis media: review of treatment recommendations. Clin Ther. 2000;22:29-39.

3. Duncan BB, Schmidt MI. Medicina baseada em evidências. In: Duncan BB, Schmidt MI, Giugliani ERJ. Medicina ambulatorial: condutas de atenção primária baseadas em evidências. $3^{a}$ ed. Porto Alegre: Artmed; 2004. p. 31-40.

4. Kraemer JK, Richardson MA, Weis NS, Furukawa CT, Shapiro GG, Pierson WE, et al. Risk factors for persistent middle-ear effusions. JAMA. 1983;249:1022-5.

5. Pukander J, Karma P. Persistence of middle-ear effusion and its risk factors after an acute attack of otitis media with effusion. In: Lim DJ, Bluestone CD, Klein JO, Nelson JD, editors. Recent advances in otitis media. Proceedings of the Fourth International Symposium. Toronto: BC Decker; 1988. p. 8-11.

6. Tomonaga K, Krono Y, Mogi G. The role of nasal allergy in otitis media with effusion: a clinical study. Acta Otolaryngol Suppl. 1988;458:41-7.

7. Bernstein JM, Lee J, Conboy K, Ellis E, Li P. The role of IgE mediated hypersensivity in recurrent otitis media with effusion. Am J Otol. 1983;5:66-9.

8. Pukander J, Luotonem J, Timonen M, Karma P. Risk factor affecting the occurrence of acute otitis media among 2-3 yearold urban children. Acta Otolaryngol. 1985;100:260-5.

9. Stahberg MR, Ruskanen O, Virolainen E. Risk factors for recurrent otitis media. Pediatr Infect Dis. 1986;5:30-2.

10. Bluestone CD. Studies in otitis media: Children's Hospital of Pittsburgh - University of Pittsburgh Progress Report - 2004. Laryngoscope. 2004;114(suppl 105):1-26.

11. Paradise $\mathrm{JL}$, Bluestone $C D$. Early treatment of the universal otitis media of infants with cleft palate. Pediatrics. 1974;53:48-54.

12. Frable MA, Brandon GT, Theogaraj SD. Velar closure and ear tubings as a primary procedure in the repair of cleft palates. Laryngoscope. 1985;95:1044-6.

13. Doyle WJ, Reilly JS, Jardini L, Rovnak S. Effect of palatoplasty on the function of the Eustachian tube in children with cleft palate. Cleft Palate J. 1986;23:63-8.

14. Boston M, McCook J, Burke B, Derkay C. Incidence of and risk factors for additional tympanostomy tube insertion in children. Arch Otolaryngol Head Neck Surg. 2003;129:293-6.

15. Balkany TJ, Downs MP, Jafek BW, Krajicek MJ. Otologic manifestations of Down syndrome. Surg Forum. 1978;29: 582-5.

16. White $B L$, Doyle WJ, Bluestone CD. Eustachian tube function in infants and children with Down syndrome. In: Lim DJ, Bluestone CD, Klein JO, Nelson JD, editors. Recent advances in otitis media with effusion. Proceedings of the Third International Symposium. Philadelphia: BC Decker; 1984. p. 62-6.

17. Schwartz DM, Schwartz RH. Acoustic impedance and otoscopic findings in younger children with Down's syndrome. Arch Otolaryngol. 1978;104:652-6. 
18. Sando I, Takahashi $\mathrm{H}$. Otitis media in association with various congenital diseases. Ann Otol Rhinol Laryngol. 1990;99:13-6.

19. Poelmans J, Tack J, Feesnstra L. Chronic middle ear disease and gastroesophageal reflux disease: a causal relation? Otol Neurotol. 2001;22:447-50.

20. White DR, Heavner SB, Hardy SM, Prazma J. Gastroesophageal reflux and Eustachian tube dysfunction in on animal model. Laryngoscope. 2002;112:955-61.

21. Rozmanic V, Volepic M, Athel V, Bonifacic D, Velepic M. Prolonged esophageal $\mathrm{pH}$ monitoring in the evaluation of gastroesophageal reflux in children with chronic tubotympanal disorders. J Pediatr Gastroenterol Nutr. 2002;34:278-80.

22. Tasker A, Dettmar PW, Panetti M, Koufman JA, Birchall JP, Pearson JP. Reflux of gastric juice and glue ear in children. Lancet. 2002;359:493.

23. Tasker A, Dettmar PW, Panetti M, Koufman JA, Birchal JP, Pearson JP. Is gastric reflux a cause of otitis media with effusion in children? Laryngoscope. 2002;112:1930-4.

24. Antonelli PJ, Lloyd KM, Lee JC. Gastric reflux is uncommon in acute post-tympanostomy otorrhea. Otolaryngol Head Neck Surg. 2005;132:523-6.

25. Pitkaranta $A$, Kalho $K L$, Rautelin $H$. Helicobacter pylori in children who are prone to upper respiratory tract infections. Arch Otolaryngol Head Neck Surg. 2005;131:256-8.

26. Wittenborg $\mathrm{MH}$, Neuhauser EB. Simple roentgenographic demonstration of Eustachian tubes and abnormalities. Am J Roentgenol Radium Thera Nucl Med. 1963;89:1194-200.

27. Holmer B, Lindegren M, Andersen JM. PH effects on ciliomotility and morphology of respiratory mucosa. Arch Environ Health. 1977;32:216-26.

28. Cherry J, Morguiles S. Contact ulcer of the larynx. Laryngoscope. 1968;73:1937-40.

29. Howie VM, Ploussard JH. Bacterial etiology and antimicrobial treatment of exsudative otitis media: relation of antibiotic therapy to relapses. South Med J. 1971;64:233-9.

30. Pillsbury HC 3rd, Kveton JF, Sasaki CT, Frazier W. Quantitative bacteriology in adenoid tissue. Otolaryngol Head Neck Surg. 1981;89:355-63.

31. Barr GS, Coatesworth AP. Passive smoking and otitis media with effusion. BMJ. 1991;303:1032-3.

32. Gates GA, Avery CA, Prihoda TJ, Cooper JC Jr. Effectiveness of adenoidectomy and tympanostomy tubes in the treatment of chronic otitis media with effusion. N Engl J Med. 1987;317: 1444-51.

33. Maw R, Bawden R. Spontaneous resolution of severe chronic glue ear in children and the effect of adenoidectomy, tonsillectomy and insertion of ventilation tubes (grommets). BMJ. 1993;306:756-60.

34. Paradise JL, Bluestone CD, Rogers KD, Taylor FH, Colborn DK, Bochman RZ, et al. Efficacy of adenoidectomy for recurrent otitis media in children previously treated with tympanostomytube placement. Results of parallel randomized and nonrandomized trials. JAMA. 1990;263:2066-73.

35. Paradise JL, Bluestone CD, Colborn DK, Bernard BS, Smith CG, Rockette $\mathrm{HE}$, et al. Adenoidectomy and adenotonsillectomy for recurrent acute otitis media: parallel randomized clinical trial in children not previously treated with tympanostomy tubes. JAMA. 1999;282:945-53.

36. Jero J, Karma P. Bacteriological findings and persistence of middle ear effusion in otitis media with effusion. Acta Otolaryngol. 1997;529:22-6.

37. Koivunem P, Uhari M, Luotonen J, Kristo A, Raski R, Pokka T, et al. Adenoidectomy versus chemoprophylaxis and placebo for recurrent acute otitis media in children aged under 2 years: randomised controlled trial. BMJ. 2004;328:487-91.

38. Mattila OS, Joki-Erkkila VP, Kilpi T, Jokinen J, Herva E, Puhakka $\mathrm{H}$. Prevention of otitis media by adenoidectomy in children younger than 2 years. Arch Otolaryngol Head Neck Surg. 2003;129:163-8

39. Gates GA, Avery CA, Cooper JC Jr, Prihoda TJ. Chronic secretory otitis media: effects of surgical management. Ann Otol Rhinol Laryngol. 1989;138:2-32.

40. Castagno LA, Lavinsky L. Otitis media in children: seasonal changes and socioeconomic level. Int J Pediatr Otorhinolaryngol. 2002;62:129-34.

41. Casselbrant ML, Brostoff LM, Cantekin EI, Flaherty MR, Doyle $W J$, Bluestone $C D$, et al. Otitis media with effusion in preschool children. Laryngoscope. 1985;95:428-36.
42. Van Cauwenberge PB. Relevant and irrelevant predisposing factors in secretory otitis media. Acta Otolaryngol Suppl. 1984;414:147-53.

43. Alho OP, Oja $H$, Koivu M, Sorri M. Risk factor for chronic otitis media with effusion in infancy. Each acute otitis media episode induces a high but transient risk. Arch Otolaryngol Head Neck Surg. 1995;121:839-43.

44. Sarkkinen $H$, Ruuskanen $O$, Meurman $O$, Puhakkat $H$, Virolainen $\mathrm{E}$, Eskola J. Identification of respiratory virus antigen in middle ear fluids of children with acute otitis media. J Infect Dis. 1985;151:444-8.

45. Klein BS, Dollettem FR, Yolkenm RH. The role of respiratory syncytial virus and other viral pathogens in acute otitis media. J Pediatr. 1982;101:16-20.

46. Buchman CA, Doyle WJ, Skoner D, Fireman P, Gwaltney JM. Otologic manifestations of experimental rhinovirus infection. Laryngoscope. 1994;104:1295-9.

47. Bylander A. Upper respiratory tract infection and Eustachian tube dysfunction in children. Acta Otolaryngol. 1984;97:343-9.

48. Alho OP, Koivu M, Sorri M, Rantakallio P. Risk factor for recurrent acute otitis media and respiratory infection in infancy. Int J Pediatr Otorhinolaryngol. 1990;19:151-61.

49. Pukander J, Karma P, Sipila M. Occurrence and recurrence of acute otitis media among children. Acta Otolaryngol. 1982;94:479-86.

50. Karma $P$, Perala M, Kuusela AL. Morbidity of very young infants with and without acute otitis media. Acta Ototaryngol. 1989; 107:460-6.

51. Van Gauwerberg P, Kluuskens. Some predisposing factors in OME. In: Lim DJ, Bluestone CD, Klein JO, Nelson JD, editors. Recent advances in otitis media with effusion. Proceedings of the Third International Symposium. Philadelphia: BC Decker; 1984. p. 28.

52. Engel J, Anteunis L, Volovics A, Hendriks J, Marres E. Prevalence rates of otitis media with effusion from 0 to 2 years of age: healthy-born versus high-risk-born infants. Int J Pediatr Otorhinolaryngol. 1999;47:243-51.

53. Engel J, Mahler E, Anteunis L, Marres E, Zielhuis G. Why are NICU infants at risk for chronic otitis media with effusion? Int J Pediatr Otorhinolaryngol. 2001;57:137-44.

54. Zieliiuis GA, Rach GH, Van Den Broekm P. Predisposing factors for otitis media with effusion in young children. Adv Otorhinolaryngol. 1988;40:65-9.

55. Gravel JS, McCarton CM, Ruben RJ. Otitis media in neonatal intensive care unit graduates: a 1 -year prospective study. Pediatrics. 1988;82:44-9.

56. Stahlberg MR. The influence of form of day-care occurrence of upper respiratory treat infections among young children. Acta Pediatr Scand. $1980 ; 282: 1-87$.

57. Ingvarsson L. Acute otalgia in children: findings and diagnosis. Acta Pediatr Scand. 1982;71:705-10.

58. Fiellau-Nikolajsen M. Tympanometry in three-year-old children. Type of care as an epidemiological factor in secretory otitis media and tubal dysfunction in unselected populations of threeyear old children. ORL J Otorhinolaryngol Relat Spec. 1979;41:193-205.

59. Tos M, Poulsen G, Borch J. Tympanometry in 2-year-old children. ORL J Otorhinolaryngol Relat Spec. 1978;40:77-85.

60. Uhari M, Mantysaari K, Niemela M. A meta-analytic review of the risk factors for acute otitis media. Clin Infect Dis. 1996;22: 1079-83.

61. Wald ER, Dashefsky B, Byers C, Guerra N, Taylor F. Frequency and severity of infections in day care. J Pediatr. 1988;112:540-6.

62. Stool S. Otitis media. Update of a common, frustrating problem. Postgrad Med. 1989;85:40-7, 51, 53.

63. Karma P. Finish approach to the treatment of acute otitis media. Report of the Finnish consensus conference. Ann Otol Rhinol Laryngol. 1987;96(suppl 129):1-19.

64. Bluestone $C D$, Klein JO, Paradise JL, Eichenwald H, Bess FH, Downs MP, et al. Workshop on effects of otitis media on the child. Pediatrics. 1983;71:639-52.

65. Lim DJ. Recent advances in otitis media with effusion. Report of the Fourth Research Conference. Ann Otol Rhinol Laryngol. 1989;98(suppl 139):10-55.

66. Casselbrant ML, Mandel EM, Kurs-Lasky M, Rockette HE, Bluestone CD. Otitis media in a population of black American and white American infants, 0-2 years of age. Int $\mathrm{J}$ Pediatr Otorhinolaryngol. 1995;33:1-16. 
67. Daly KA, Rich SS, Levine S, Margolis RH, Le CT, Lidgren B, et al. The family study of otitis media: design and disease and risk factor profiles. Genet Epidemiol. 1996;13:451-68.

68. Daly KA, Bronwn JE, Lindgren BR, Meland MH, Le CT, Giebink GS. Epidemiology of otitis media onset by six months of age. Pediatrics. 1999;103:1158-66.

69. Vinther B, Elbrond O, Pedersen B. A population study of otitis media in childhood. Acta Otolaryngol Suppl. 1979;360:135-7.

70. Teele DW, Klein JO, Rosner B, Greater Boston Otitis Media Study Group. Epidemiology of otitis media during the first seven years of life in children in greater Boston: a prospective cohort study. J Infect Dis. 1989;160:83-94.

71. Pukander J. Clinical features of acute otitis media among children. Acta Otolaryngol. 1983;95:117-22.

72. Etzel RA. Smoke and ear effusions. Pediatrics. 1987;79:309-11.

73. Lubianca Neto JF, Arrarte JL, Brinkmann CA, Facco SR, Martins WM. A exposição ambiental ao fumo e o risco de otite média em crianças: avaliação das evidências. Rev Bras Otorrinolaringol. $1996 ; 62: 280-93$

74. Melia RJ, Florey C, Du V, Chinns $S$. The relation between respiratory illness in primary schoolchildren and the use of gas for cooking. I. Results from a national survey. Int J Epidemiol. 1978;3:333-8.

75. Black N. The aetiology of glue-ear - a case-control study. Int J Pediatr Otorhinolaryngol. 1985;9:121-33.

76. Strachan DP. Damp housing and childhood asthma: validation of reporting symptoms. BMJ. 1988;297:1223-6.

77. Strachan DP, Darvis MJ, Feyerabend C. Passive smoking, salivary cotinine concentrations and middle ear effusion in 7 year-old children. BMJ. 1989;298:1549-52.

78. Birch L, Elbrond O. A prospective epidemiological study of secretory otitis media in young children related to the indoor environment. ORL J Otorhinolaryngol Relat Spec. 1987;49:253-8.

79. Hinton $A E$, Buckley G. Parenteral smoking and middle ear effusion in children. J Laryngol Otol. 1988;102:992-6.

80. Stenstrom R, Bernard PA, Bem-Simhon H. Exposure to environmental tobacco smoke as a risk factor for recurrent acute otitis media in children under the age of five years. Int J Pediatr Otorhinolaryngol. 1993;27:127-36.

81. Kitchens GG. Relationship of environmental tobacco smoke to otitis media in young children. Laryngoscope. 1995;105:1-13.

82. Lubianca Neto JF, Burns AG, Lu L, Mombach R, Saffer M. Passive smoking and non-recurrent acute otitis media in children. Otolaryngol Head Neck Surg. 1999;121:805-8.

83. Ilicali OC, Keles N, Deer K, Asum OF, Guldiken Y. Evaluation of the effect of passive smoking on otitis media in children by an objective method: urinary cotinine analysis. Laryngoscope. 2001; 11:163-7.

84. Lieu JE, Feinstein AR. Effect of gestational and passive smoke exposure on ear infections in children. Arch Pediatr Adolesc Med. 2002;156:147-54.

85. Iversen M, Birch L, Lundquist GR, Elbrond O. Middle ear effusion in children and the indoor environment: an epidemiological study. Arch Environ Health. 1985;40:74-9.

86. Henderson FW, Collier AM, Sanyal MA, Watkins JM, Fairclough $\mathrm{DL}$, Clyde WA Jr, et al. A longitudinal study of respiratory viruses and bacteria in the etiology of acute otitis media with effusion. N Engl J Med. 1982;306:1377-83.

87. Alho O, Kikku O, Oja H, Koivu M, Sorri M. Control of the temporal aspect when considering risk factor for acute otitis media. Arch Otolaryngol Head Neck Surg. 1993;119:444-9.

88. Owen MJ, Baldwin CD, Swank PR, Pannu AK, Johnson DL, Howie VM. Relation of infant feeding practices, cigarette smoke exposure, and group child care to the onset and duration of otitis media with effusion in the first two years of life. J Pediatr. 1993;123:702-11.

89. Ey JL, Holberg CJ, Aldous MB, Wright AL, Martinez FD, Taussig LM. Passive smoke exposure and otitis media in the first year of life. Pediatrics. 1995;95:670-7.
90. Duncan B, Ey JL, Holberg CJ, Wright AL, Martinez FD, Taussig LM. Exclusive breast-feeding for at least 4 months protects against otitis media. Pediatrics. 1993;91:867-72.

91. Collet JP, Larson CP, Boivin JF, Suissa S, Pless IB. Parental smoking and risk of otitis media in pre-school children. Can J Public Health. 1995;86:269-73.

92. Strachan DP, Cook DG. Health effects of passive smoking. 4. Parental smoking, middle ear disease and adenotonsillectomy in children. Thorax. 1998;53:50-6.

93. Fielding JE, Phenow KJ. Health effects of involuntary smoking. N Engl J Med. 1988;319:1452-60.

94. Blakley BW, Blakley JE. Smoking and middle ear disease: are they related? A review article. Otolaryngol Head Neck Surg. 1995; 112:441-6.

95. Saarinen UM. Prolonged breast feeding as prophylaxis for recurrent otitis media. Acta Pediatr Scand. 1982;71:567-71.

96. Cunningham AS. Morbidity in breast-fed and artificially fed infants. II. J Pediatr. 1979;95:685-9.

97. Chandra RK. Prospective studies of the effect of breast feeding on incidence of infection and allergy. Acta Pediatr Scand. 1979;68:691-4.

98. Saffer M. Avaliação dos sintomas e sinais otomicroscópicos no diagnóstico clínico da otite media aguda em crianças [tese de mestrado]. Rio de Janeiro: Universidade Federal do Rio de Janeiro; 1990.

99. Duncan B, Ey J, Holberg CJ, Wright AL, Martinez FD, Taussig LM. Exclusive breastfeeding for at least 4 months protects against otitis media. Pediatrics. 1993;91:867-72.

100. Duffy LC, Faden H, Wasielewski R, Wolf J, Krystofik D. Exclusive breastfeeding protects against bacterial colonization and day care exposure to otitis media. Pediatrics. 1997;100:E7.

101. Harsten G, Prellner K, Heldrup J, Kalm O, Kornfalt R. Recurrent acute otitis media. A prospective study of children during the first three years of life. Acta Otolaryngol. 1989;107:111-9.

102. Tainio VM, Savilahti E, Salmenpera L, Arjomaa P, Siimes MA, Perheentupa J. Risk factors for infantile recurrent otitis media: atopy but not type of feeding. Pediatr Res. 1988;23:509-12.

103. Duncan RB. Positional otitis media. Arch Ototaryngol. $1960 ; 72: 454-63$.

104. Beauregard RB. Positional otitis media. J Pediatr. 1971;79: 294-6.

105. Sassen ML, Brand R, Grote JJ. Breast-feeding and acute otitis media. Am J Otolaryngol. 1994;15:351-7.

106. Niemela M, Uhari M, Hannuksela A. Pacifiers and dental structure as risk factors for otitis media. Int J Pediatr Otorhinolaryngol. 1994;29:121-7.

107. Niemela M, Uhari M, Mötönen M. A pacifier increases the risk of recurrent acute otitis media in children in day-care centers. Pediatrics. 1995;96:884-8.

108. Warren JJ, Levy SM, Kirchner HL, Nowak AJ, Bergus GR. Pacifier use and the occurrence of otitis media in the first year of life. Pediatr Dent. 2001;23:103-7.

109. Niemela M, Pihakari O, Pokka T, Uhari M. Pacifier as a risk factor for acute otitis media: a randomized, controlled trial of parental counseling. Pediatrics. 2000;106:483-8.

110. Alho OP, Laara $\mathrm{E}, \mathrm{Oja} \mathrm{H}$. Public health impact of various risk factors for acute otitis media in northern Finland. Am J Epidemiol. 1996;143:1149-56.

111. Uhari M, Mottonen M. An open randomized controlled trial of infection prevention in child day-care centers. Pediatr Infect Dis J. $1999 ; 18: 672-7$.

Correspondence:

José Faibes Lubianca Neto

Rua Dona Laura, 320/90 andar, Rio Branco

CEP 90430-090 - Porto Alegre, RS - Brazil

Tel.: + 55 (51) 3029.3399

E-mail: jlubianc@terra.com.br 